\title{
NUEVOS REGISTROS DEL GÉNERO CISSAMPELOS (MENISPERMACEAE) PARA LA FLORA ARGENTINA
}

\author{
MARÍA PEÑA-CHOCARRO ${ }^{1}$ \& JUANA DE EGEA²
}

\begin{abstract}
Summary: Peña-Chocarro, M. \& J. De Egea. 2015. New records of the genus Cissampelos (Menispermaceae) for the flora of Argentina. Bonplandia 24(1): 37-42.

Cissampelos andromorpha DC. and C. arenicola M. Nee \& R. Ortiz are cited for the first time for the Argentinian flora. Descriptions and images of herbarium specimens of the species are presented and their geographical distributions are updated. A key to the four species of Cissampelos occurring in Argentina is included.
\end{abstract}

Key words: Argentina, Cissampelos, flora, Menispermaceae.

Resumen: Peña-Chocarro, M. y J. De Egea. 2015. Nuevos registros del género Cissampelos (Menispermaceae) para la flora Argentina. Bonplandia 24(1): 37-42.

Cissampelos andromorpha DC. y C. arenicola M. Nee \& R. Ortiz se citan por primera vez para la flora Argentina. Se presentan descripciones e imágenes de pliegos de herbario de las especies mencionadas y se actualizan sus distribuciones geográficas. Se incluye una clave para la identificación de las cuatro especies de Cissampelos presentes en Argentina.

Palabras clave: Argentina, Cissampelos, flora, Menispermaceae.

\section{Introducción}

E1 género Cissampelos L. comprende aproximadamente 21 especies distribuidas en zonas tropicales (Mabberley, 2008; Ortiz \& Nee, 2014). Son bejucos poco leñosos, con una sola especie herbácea perenne $(C$. ovalifolia DC.), generalmente de zonas abiertas (sabanas, bordes de caminos, zonas perturbadas, dunas arenosas) y bosques.

En la última revisión del género, Rhodes (1975) menciona 20 especies, 9 para América, 9 para África, una especie asiática y otra, $C$. pareira L., pantropical, única citada en este trabajo, para Argentina.
Barneby (1975) incluyó a Argentina septentrional en el área de distribución de $C$. ovalifolia, pero sin citar material de referencia. La presencia de esta especie en el territorio argentino fue confirmada posteriormente por Keller \& Tressens (2008) quienes citan varios ejemplares para la provincia de Misiones. Ambas especies, $C$. pareira y C. ovalifolia, son la únicas de este género citadas para Argentina en el catálogo de plantas vasculares del Cono Sur (Zuloaga et al., 2008; Zuloaga \& Belgrano 2014).

Durante la revisión de la familia Menispermaceae para la Flora del Paraguay fueron encontrados varios pliegos de herbario

${ }^{1}$ The Natural History Museum, BM, Cromwell Rd, London SW7 5BD. Correo electrónico: M.Pena@nhm.ac.uk.

${ }^{2}$ Investigadora asociada del Centro para el Desarrollo de la Investigación Científica (CEDIC/Díaz Gill Medicina Laboratorial/Fundación Moisés Bertoni), Investigadora Nivel I del PRONII, CONACYT. Asunción, Paraguay. Correo electrónico: juana.deegea@gmail.com. 
que confirman la presencia de otras dos especies de este género hasta ahora no citadas para Argentina: C. andromorpha DC. y $C$. arenicola M. Nee \& R. Ortiz.

Cissampelos andromorpha había sido recolectada hasta ahora en Mesoamérica, Colombia, Venezuela, Guyana Francesa, Ecuador, Perú, Bolivia y Brasil (Barneby, 1975; Rhodes, 1975; Ortiz, 2011). Cissampelos arenicola es una especie descrita muy recientemente (Ortiz \& Nee, 2014) para la zona del Chaco Seco paraguayo y boliviano.

Se presentan descripciones e imágenes de pliegos de herbario de estos nuevos registros para el país. Así mismo se incluye una clave para facilitar la identificación de las cuatro especies citadas hasta ahora para Argentina.

\section{Resultados}

\section{Tratamiento taxonómico}

Cissampelos andromorpha DC., Syst. Nat. 1: 539. 1817. Typus: Guayana Francesa. Cayenne, Patris s.n. (holotypus G-DC). (Fig. 1)

Iconografía: Rhodes, Phytologia 30: 442, t. 9. 1975.

Bejucos perennes. Tallos estriados, ralamente pubescentes a glabros, el indumento plateado, corto y adpreso. Hojas (3-) 7-11 $(-14,5) \times(3-)$ 6-9 (-12) cm, ovadas, base truncada a cordada, márgenes enteros a escasamente ondulados, ápice acuminado a obtuso, mucronado, 5-palmatinervadas, membranáceas a subcoriáceas, glabras a pilosas en la haz, puberulentas a densamente pilosas en el envés, subbasifijas a brevemente peltadas; pecíolos (4-) 5-8 (-13) cm, tomentosos a glabrescentes, el pulvínulo basal conspicuo y torcido. Inflorescencias con flores estaminadas de hasta $26 \mathrm{~cm}$ long., frecuentemente saliendo de ramas de años anteriores, en racimos de dicasios axilares y laxos, escasamente setulosos a glabrescentes; pedúnculos 1,5-2 cm long.; brácteas 5-13 $\times$ 4-13 mm, ovadas, mucronadas, basifijas, pilosas; bractéolas $1 \mathrm{~mm}$ long., usualmente caducas, lanceoladas; pedicelos 1,5-2,2 mm long. Flores estaminadas hasta $2 \mathrm{~mm}$ diám.; sépalos 4, disperso-setulosos exteriormente; corola cupuliforme, raramente pateliforme, pétalo uno, glabro; sinandro con 4 anteras connadas. Inflorescencias con flores pistiladas 4-6 cm long., pseudo-racemosas, axilares en hojas adultas, setulosas a glabrescentes, generalmente ebracteadas; brácteas 2-8 mm, ovadas; flores 4-6, fasciculadas. Flores pistiladas hasta $2 \mathrm{~mm}$ de diámetro; sépalo uno, escasamente seríceo exteriormente; pétalo uno, glabro; carpelo tomentoso. Drupa 4-7 × 4-5 $\mathrm{mm}$, obovoide a subglobosa, roja en la madurez; endocarpo óseo, externamente denticulado, con proyecciones dorsales y laterales.

Obs. fenológicas: De acuerdo con los ejemplares examinados del Cono Sur, el periodo de floración se extiende desde octubre a diciembre (flores estaminadas) y hasta febrero (flores pistiladas).

Distribución geográfica y ecología: Mesoamérica (Guatemala, Nicaragua, Costa Rica, Panamá), Colombia, Venezuela, Guyana Francesa, Ecuador, Perú, Bolivia, Brasil y Argentina. Habita bosques húmedos de zonas bajas y bosques secundarios. En Argentina fue coleccionada en las provincias de Misiones y Corrientes, en ambientes asociados a la Selva Paranaense, tanto en el interior de la selva, como en bordes de bosque y bosques de galería.

Material examinado. ARGENTINA. Corrientes: Dep. Santo Tomé, Establecimiento Las Marías, Ruta Nac. N ${ }^{\circ} 14,7$ km S de Gdor. Virasoro, 2-XII-1970, flô, Krapovickas et al. 16908 (CTES); Ruta 37, 5 km E de Gdor. Virasoro, 14-XI-1974, flō, Schinini \& Carnevali 10639 (CTES). Misiones: Dep. Guaraní, Predio Guaraní, Faja de enriquecimiento "Loro blanco" a ca. $500 \mathrm{~m}$ de vivienda de huéspedes, 26⒌'59'S, 5412'18”'W, fl ${ }^{\lambda}, 2-X I-1999$, Tressens et al. 6435 (CTES); Dep. Iguazú, Puerto Bosetti, Cuartel Uruzú, cercanías a perilago Urugua-i, borde de faja ecológica en plantación de Pinus, fl $\partial^{\lambda}, 22-X I-2005$, Keller 3239 (CTES). BOLIVIA. La Paz: Mapiri,

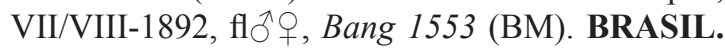
Amazonas: Prope San Gabriel da Cachoeira, ad Rio Negro, I-VIII-1852, floq, Spruce 2164 (BM); Mun. Humayta, near Tres Casas, on varzea land, 14-IX/11-X-1934, flô,, Krukoff 6521 (BM); Mun. 


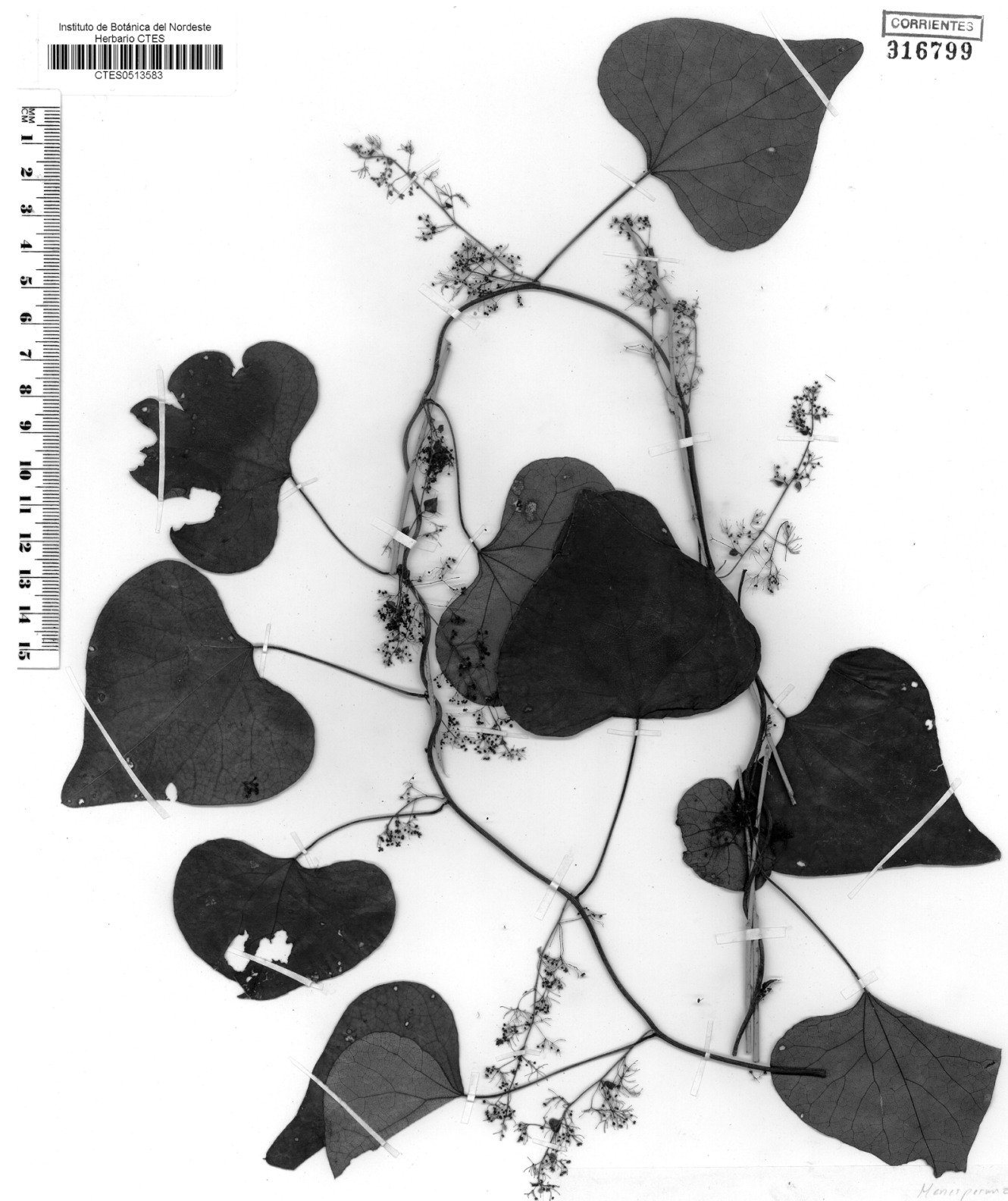

HERBARIO DEL INSTTUTTO DE BOTANICA DEL NORDESTE (CTES) Corrientes - Rep. Argentina

Cissampelos pareira I.

Det. ㅍ. Keller, 2000

Det: J. De Egea \& M. Peña Chocallo
Cissampelos audromonpha DC.
Fecha: $\times .2014$

ARGENTINA, Misiones, Dep. Guarani

Loc. Predio Guarani, $26^{\circ} 54^{\prime}-59^{\prime s}, 54^{\circ} 18^{\prime}$ W. Faja de enriquecimiento 'Loro blanco" a ca $500 \mathrm{~m}$ de Vivienda de huéspedes.

Interior de selva.

Obs. Voluble. Inflorescencias verdosas.

Leg. S.G.Tressens, H. Keller, V. Maruñak, V. Revilla y F. Robledo

Fecha 2-11-1999 $\mathbf{N}^{\circ} 6435$

Fig. 1. Cissampelos andromorpha. Fotografía del ejemplar de herbario colectado en la provincia de Misiones (Tressens et al. 6435, CTES). 
Humayta, near Livramento on rio Livramento, on terra firme, 12-X/6-XI-1934, fl §̄, Krukoff 6690 (BM). Minas Gerais: Agricultural College land, hillside of Cha-Cha valley in cut-over woods, 1-III1930, flo, Mexia 4410 (BM); Fazenda de F. Lopez, Pau Daa, cut-over woods, 11-XI-1930, flô, Mexia 5281 (BM). Pará: Ad ripas fluminis das Trombétas et lacus Quiriquiry, XII-1849, fl $\partial^{\lambda}$, Spruce s.n. (BM). Paraná: Pena do Haz ad marginem silvulae, 6-II-1908, flor, Dusén 6997 (BM); Bariguy in silva, 29-X-1914, flô, Dusén 15772 (BM); Mun. Curitiba, Cidade Industrial, 18-XI-1987, fl ${ }^{\widehat{ }}$, Silva \& Ribas 412 (CTES). COLOMBIA. Putumayo: Umbría $0^{\circ} 54^{\prime} \mathrm{N}, 76^{\circ} 10^{\prime} \mathrm{W}, \mathrm{X} / \mathrm{XI}-1930$, fl , Klug 1656 (BM). PERU. Loreto: Balsapuerto, forest, II-1933, fl $\partial^{\lambda}$, Klug 2893 (BM). VENEZUELA. Amazonas: Ad fluminis Casiquiari, Pasibi et

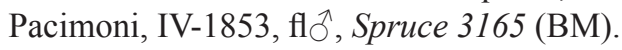

Cissampelos arenicola M. Nee \& R. Ortiz, Phytokeys 38: 89-99. 2014. Typus: Bolivia. Santa Cruz: Along hwy from Santa Cruz to Abapó, $3 \mathrm{Km} \mathrm{S}$ of crossing of railroad and 2 km S of bridge over Quebrada Peji, 1-V-2001, M. Nee, S. Knapp \& J.M. Mendoza 51717 (holotypus USZ, isotypi LBP, MO). (Fig. 2)

Bejucos perennes, dioicos, raramente monoicos. Tallos estriados, los leñosos glabrescentes y los subherbáceos y herbáceos con pilosidad más o menos plateada. Hojas 0,8-3 (-4) × 1,3-4 (-5,6) $\mathrm{cm}$, generalmente más anchas que largas, las asociadas a las inflorescencias menores, ovado- a subreniforme-trilobadas, lóbulos redondeados, el terminal mucronado, 6-palmatinervadas, cartáceas a subcoriáceas, glaucas, espaciadamente pilosas a glabrescentes en ambas superficies, basifijas o subpeltadas; pecíolo 0,5-1,7 cm long., pulvinado en ambos extremos. Inflorescencias estaminadas en dicasios o monocasios axilares con pubescencia plateada; pedúnculos 1-5 mm long.; brácteas lineares 0,4-1,5 $\mathrm{mm}$ long. Flores estaminadas 5-6 (17), de unos $2 \mathrm{~mm}$ diám., brevemente pediceladas; sépalos 4-6, pilosos externamente; pétalo generalmente único, menos frecuentemente 3-4, esparcidamente pilosos exteriormente; sinandro con (6) 8 (10) anteras connadas. Inflorescencias pistiladas axilares, con 3-5 flores fasciculadas, espaciadamente pilosoplateadas. Flores pistiladas de 1,5 $\mathrm{mm}$ long., pediceladas; sépalos 1(2), pilosos; pétalos 1(3), externamente pilosos; sépalo y pétalos tempranamente caducos; carpelo 1, giboso, piloso-plateado. Drupa de unos $8 \mathrm{~mm}$ diám., globosa, glabra, naranja o roja en la madurez; endocarpo bilateralmente comprimido, moderadamente ornamentado, con una perforación diminuta en las caras laterales.

Obs. fenológicas: Según Nee \& Ortiz (2014) y de acuerdo con los ejemplares examinados, el periodo de floración incluye los meses de febrero, mayo, noviembre y diciembre (flores estaminadas) y febrero, abril, mayo, junio y diciembre (flores pistiladas).

Distribución geográfica y ecología: Sur de Bolivia, NO de Paraguay y N de Argentina. Ortiz \& Nee (2014) mencionan que C. arenicola estaría restringida a sitios con suelos arenosos y dunas. Todos los ejemplares examinados fueron colectados dentro del área de la región fitogeográfica chaqueña (Cabrera, 1976), en ambientes de sabanas y dunas arenosas. El ejemplar de Salta, que constituye la nueva mención para la flora Argentina, fue colectado en "aibales", nombre utilizado localmente para designar a las sabanas dominadas por "aibe" o Elionurus muticus (Spreng.) Kuntze (Morello \& Adámoli, 1974), desarrolladas típicamente sobre suelos arenosos.

Material examinado. ARGENTINA. Salta: Dep. Rivadavia, Ruta Nac. 81, $10 \mathrm{~km}$ E de Los Blancos, en aibal, 7-V-1998, flô, Krapovickas et al. 47257 (CTES). PARAGUAY. Boquerón: Ruta Transchaco, en lomada con suelo arenoso, $20^{\circ}$ 40’ S, 62 ${ }^{\circ} \mathrm{W}, 12-\mathrm{XII}-1987$, fl $+\mathrm{fr}$, Schinini \& Palacios 25707 (CTES, G); Ruta Transchaco, 10 km NW de Nueva Asunción, dunas consolidadas, 14-V-1994, floffr, Krapovickas et al. 45428 (CTES, G); Ruta Transchaco a partir del Km 702, entre PN Tte. Enciso y PN Médanos del Chaco, ambiente ruderal, 20 36' 19''S, 62 02' 54' W, 22-II-2006, flô, De Egea et al. 923 (FCQ, BM, CTES, G, MO, PY, SI, UNR). Presidente Hayes: Tyto. VillazónFortín Guaraní, en espartillar arenoso, 2-V-1993, $\mathrm{fl}$ + fr, Mereles \& Degen 5075 (CTES, FCQ, MO). 


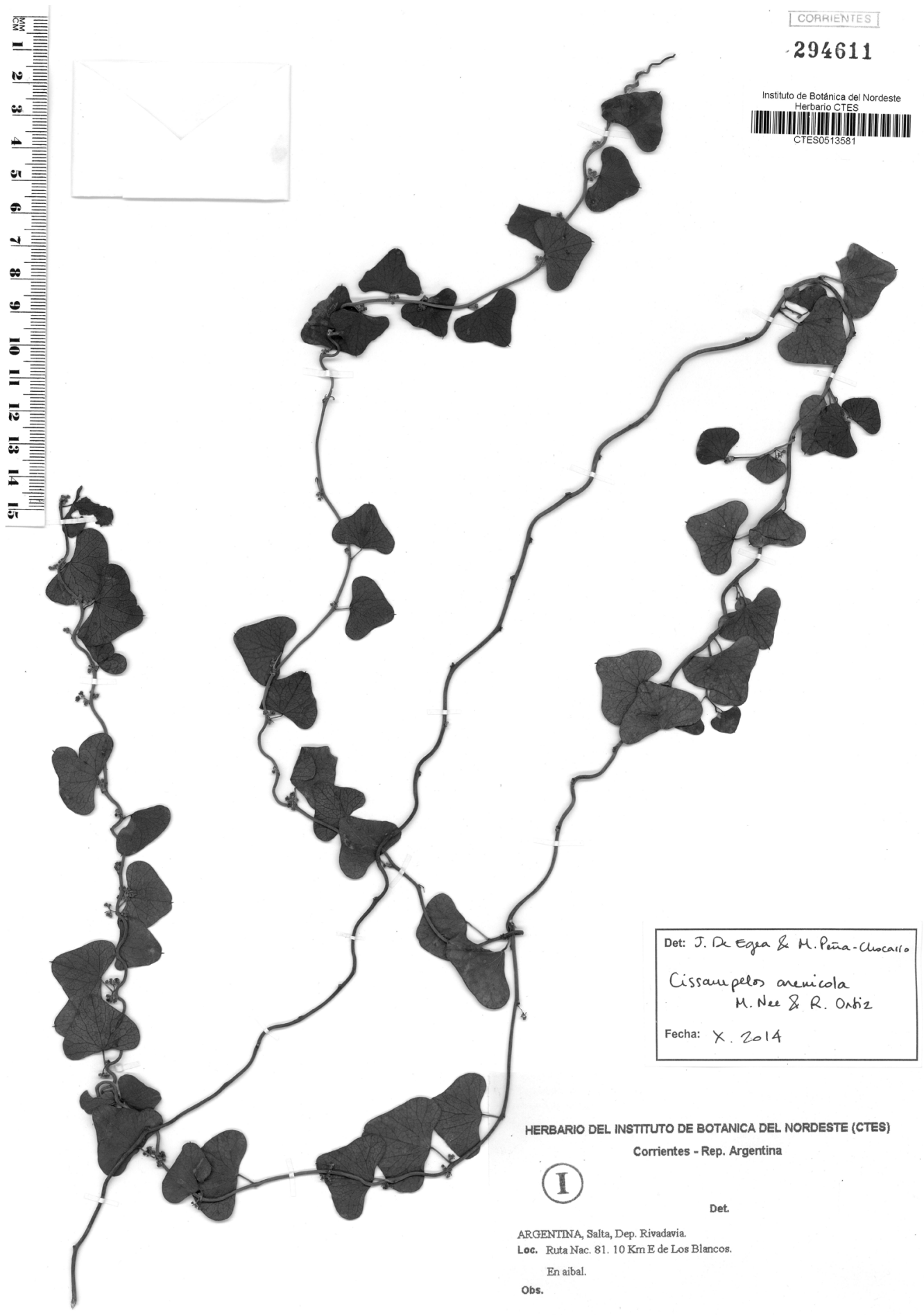

Leg. A. Krapovickas, A. Schinini y G. Seijo

Fecha 7-5-1998

$N^{\circ} 47257$

Fig. 2. Cissampelos arenicola. Fotografía del ejemplar de herbario colectado en la provincia de Salta (Krapovickas et al. 47257, CTES). 


\section{Clave para identificación de las especies argentinas de Cissampelos}

1. Plantas erectas.

C. ovalifolia

1a. Plantas trepadoras. C. arenicola

2. Hojas marcadamente trilobadas, más anchas que largas; sinandro (6-) 8 (-10) locular 2

2a. Hojas ovadas, cordadas a suborbiculares, no marcadamente trilobadas; sinandro 4-locular. 3

3. Hojas ovadas a cordadas. Hojas, tallos e inflorescencias glabras a pilosas. Flor estaminada con corola cupuliforme. C. andromorpha

3a. Hojas cordadas a suborbiculares. Hojas, tallos e inflorescencias densamente pilosas a tomentosas. Flor estaminada con la corola pateliforme. C. pareira

\section{Bibliografía}

BARNEBY, R. C. 1975. Menispermáceas. En Reitz, P. R. Fl. Il. Catarin. MENI: 3-40.

CABRERA, A. L. 1976. Regiones fitogeográficas argentinas. Enc. Arg. Agr. y Ganadería. 2da. Ed., 2 (1): $1-85$.

KELLER, H. S. \& S. G. TRESSENS. 2008. Primer registro para la Argentina de dos especies de uso medicinal. Bol. Soc. Argent. Bot. 43: 171-178.

MABBERLEY, D. J. 2008. Mabberley's Plant Book: a portable dictionary of plants, their classification and uses. 3rd ed. Cambridge University Press. $1021 \mathrm{pp}$.

MORELLO J. \& J. ADÁMOLI. 1974. La vegetación de la República Argentina. Las grandes unidades de vegetación y ambiente del Chaco Argentino. Segunda Parte: Vegetación y ambiente de la provincia del Chaco. Centro de Investigaciones de
Recursos Naturales. Instituto Nacional de Tecnología agropecuaria. Serie Fitogeográfica 13: 96-97.

ORTIZ, R. S. 2011. http://www.tropicos.org/docs/meso/ menispermaceae.pdf.

ORTIZ, R. S. \& M. H. NEE. 2014. A new species of Cissampelos (Menispermaceae) from Bolivia and Paraguay. Phytokeys 38: 89-99.

RHODES, D. C. 1975. A revision of the genus Cissampelos. Phytologia 30: 415-483.

ZULOAGA, F. O., O. MORRONE \& M. J. BELGRANO (eds.). 2008. Catálogo de las Plantas Vasculares del Cono Sur (Argentina, Sur de Brasil, Chile, Paraguay, y Uruguay). Volumen III. Monogr. in Syst. Bot. Missouri Bot. Gard. 107: 2413-2424.

ZULOAGA, F. O. \& M. J. BELGRANO (eds.). 2014. Catálogo de las Plantas Vasculares del Cono Sur. Disponible en http://www.darwin.edu.ar/Proyectos/ FloraArgentina/FA.htm. [Acceso: 10-Octubre-2014]

Original recibido el 4 de noviembre de 2014; aceptado el 10 de abril de 2015. 